\title{
Editorial
}

\section{El pulso de la crisis: entre la convicción y la responsabilidad}

\author{
C. Martínez González \\ Pediatra. CS San Blas. Parla, Madrid. España.
}

\begin{abstract}
Publicado en Internet:
5-febrero-2013

Carmen Martínez González: carmendiri@gmail.com
\end{abstract}

Por primera vez, una crisis económica y sus respuestas tendrán consecuencias negativas para la salud en los países desarrollados, aumentando las inequidades. Una situación que choca frontalmente con los recientes objetivos de la Organización Mundial de la Salud $(\mathrm{OMS})^{1}$ para Europa: reducir las inequidades en salud, fortalecer la salud pública y asegurar servicios de salud universales, centrados en la persona, equitativos, sostenibles y de calidad. Margaret Chan, su Directora General, destaca que mejorar la salud y el bienestar debe ser un derecho y que esto no depende tanto de la economía como del abordaje de las causas de la enfermedad y las inequidades a través de los determinantes sociales.

Las inequidades en salud son diferencias entre grupos humanos fruto de una distribución desigual, e injustificada, de bienes y servicios. Causan morbilidad y mortalidad y son subsanables con acciones razonables. Su persistencia es sencillamente injusta y su reducción un imperativo ético.

Este escrito no es el contexto para analizar los errores políticos, las medidas de contención o las insostenibles tendencias sociales que han generado esta crisis. Pero es cierto que la salud depende, ahora más que nunca, de factores que responden al acrónimo EPIC: economía, política y políticas, instituciones y costes ${ }^{2}$. Sin dinero, planes y políticas públicas e instituciones que las Ileven a cabo, no puede haber salud. Si el sistema no es sosteni- ble económicamente, tampoco. Un acrónimo que parece aludir irónicamente a una situación "épica", donde falta un elemento clave: los profesionales sanitarios. Profesionales que en este contexto acumulamos razones para la desmotivación, a la vez que tenemos la convicción de no poder consentir la decadencia del Sistema Nacional de Salud, ni la descalificación sistemática de lo público para justificar su liquidación. Sin duda este es un tiempo sombrío, donde el impulso de la ética (en concreto, de la ética de la responsabilidad) puede aportar luz y conjurar la desmotivación personal y el desánimo colectivo.

Entre las diferentes corrientes que existen, la ética de la responsabilidad es la que ha liderado la reflexión filosófica y ética desde que Max Weber dijera en su conferencia "El político y el científico" (1919), que "cualquier acción orientada éticamente puede ajustarse a dos máximas: la ética de la convicción o la ética de la responsabilidad".

La ética de la convicción tiende a certezas, valores y juicios absolutos; a posturas inflexibles y verdades dogmáticas que dificultan los acuerdos. Desde la ética de la responsabilidad, sin embargo, los principios se contextualizan, se flexibilizan matizados por las consecuencias y la necesidad de buscar acuerdos al margen de ideologías. No es que la ética de la convicción carezca por completo de responsabilidad, ni la ética de la responsabilidad de convicciones. Pero podríamos decir que la ética 
que lidera responsabilidades es más constructiva que la que abandera convicciones.

Este puede ser un tiempo de valientes, atrevidos a revitalizar los valores propios de toda profesión como el altruismo (no ingenuidad), la disciplina (no obediencia), la eficiencia (con recursos limitados), el compromiso ${ }^{3}$ y la lealtad. Tiempo de reanimar la profesionalidad (professionalism) ${ }^{4}$ o conjunto de principios y compromisos orientados a mejorar la salud del paciente maximizando su autonomía, creando relaciones caracterizadas por la integridad, la práctica ética, la justicia social y el trabajo en equipo. O puede ser un tiempo de mediocres, que, justificados por la crisis, olvidemos que el desempeño de nuestra profesión con pleno rendimiento es un deber moral.

Cuando firmamos nuestro contrato asumimos compromisos laborales, pero al elegir esta profesión nos comprometemos con sus competencias específicas, con el mantenimiento de la confianza del paciente y de la sociedad, y con responsabilidades específicas como la docencia. Recordemos que doctor viene del latín docere, que significa enseñar (sin embargo, la docencia a los residentes está siempre en juego como moneda de cambio ante las dificultades).

Nos comprometen los pacientes y la sociedad, pero también las instituciones de las que depende nuestro (menguado) salario y la estabilidad del sistema público de salud. Resolver los inevitables conflictos de lealtad que genera la situación crítica actual sin sembrar la desconfianza en los pacientes es difícil pero necesario.

Los profesionales que asumen esta profesionalidad, además de trabajar, innovar e intentar ser creativos, reconocen los aciertos de los demás y hacen posible la convivencia en condiciones de profundo desacuerdo. Buscan los bienes externos de su profesión (fundamentalmente los económicos, obviamente necesarios) pero también los bienes internos, los que dan sentido y legitimidad social a la profesión.

Los mediocres caen en la indolencia ("para lo que me pagan"), consienten la ineficiencia y justifican las actitudes negativas hacia los pacientes en función del malestar laboral. No suelen reconocer el éxito académico ni laboral de sus compañeros. Tienen un sentido más burocrático de la responsabilidad y se instalan en la queja como elemento aglutinador.

Indudablemente, mantener la profesionalidad es un desafío en este momento en el que el sistema no sabe retener, valorar ni motivar a unos profesionales formados magníficamente e imprescindibles para mantener una sanidad pública de calidad.

Los pediatras de Atención Primaria somos observadores privilegiados de ese "cuarto mundo" insertado en el "primero", de los determinantes sociales de la salud, de la vulnerabilidad y el riesgo de exclusión social ${ }^{5}$. Todo ello incrementado por el debilitamiento del estado de bienestar, la precarización del trabajo y el aumento de estructuras de convivencia con menos apoyos internos, especialmente las familias monoparentales.

Vivimos con preocupación el riesgo de pobreza, que alcanza el 26,2\% en cifras de UNICEF ${ }^{6}$, definido por el umbral del $60 \%$ de la mediana de los ingresos de los hogares en España. Para comprender el significado y alcance real de este indicador hay que valorar, sin embargo, algunos matices; con este indicador, países con individuos muy igualados en renta (independientemente de su nivel global) pueden tener pocos hogares con ingresos menores del $60 \%$ de la mediana (casi no tendrían pobres, según este indicador), mientras que, paradójicamente, en países donde todos son muy pobres, habría, también, pocos por debajo del $60 \%$ de la mediana. Incluso podría ocurrir que los pobres de un país como el nuestro sean más ricos que los ricos de otros países, porque este análisis refleja desigualdad más que pobreza, lo cual no es menos preocupante. En esta línea expresaba Martha C. Nussbaum, en la entrega del premio Príncipe de Asturias de Ciencias Sociales de 2012, que los indicadores económicos basados en el producto interior bruto no son suficientes para evaluar la calidad de vida, porque omiten la distribución de la riqueza y la reducen a un concepto excesivamente técnico ${ }^{7}$. 
Indudablemente, hay que evaluar en términos objetivos las consecuencias negativas de las crecientes desigualdades y de la reducción del gasto público directa o indirectamente relacionado con la infancia. Pero también hay que rescatar de este informe las percepciones positivas de los propios niños: "Muchas familias comen en casa todos juntos porque prefieren no pagar el comedor y hacer la comida en casa" (esto supone mayor comunicación familiar), "los niños tenemos que entender la nueva situación y tenemos que buscar actividades de ocio más baratas y creativas y que sean divertidas; también existe el trueque: cambiar las cosas que nos sobran por otras que necesitamos sin necesidad de dinero así podemos ayudar a la gente y cambiar cosas que no nos sirven por otras útiles".

Desde nuestras consultas, sentimos que la crisis económica pone en riesgo los derechos humanos, pero sabemos que estos no dependen tanto de nosotros como de la voluntad política. No obstante, alguno como el derecho al respeto, lo construimos nosotros mismos, y seguramente todos reconocemos expresiones xenófobas ("moro", "sudaca") y estigmatizantes ("nosotros pagamos, a ellos se les atiende gratis") que solemos tolerar con exasperante normalidad. Actitudes que deberían llamarse "aporofobias" (rechazo al pobre), que traspasan claramente la línea que separa la opinión de la discriminación.

La xenofobia aumenta el riesgo de exclusión y marginación. Si ya era preocupante que en 2003 el $52 \%$ de los españoles sintiera poca o ninguna simpatía por los gitanos, el $46 \%$ por los musulmanes, el $31 \%$ por los inmigrantes y el $25 \%$ hacia los homosexuales $^{8}$, en 2008 el $66 \%$ opinaba que hay bastante o mucha discriminación racial y étnica. Esto que piensan los adultos, lo perciben, lo aprenden y lo reproducen los niños.

Cuesta admitirlo, pero no es fácil mirar con optimismo los objetivos de la OMS, basados en valores tan sólidos como la solidaridad, la sostenibilidad, la equidad o la atención sanitaria como derecho humano fundamental.

La crisis, inicialmente económica, está evolucionando hacia una fractura de la cohesión social ${ }^{9}$. Y no avanzamos precisamente hacia la desaparición de las desigualdades en salud generadas por los determinantes sociales, "las causas de las causas de la mala salud"10. Por otro lado, es justo reconocer que en los últimos años han proliferado las intervenciones médicas ineficientes y un alienante consumismo sanitario. Factores que no son ni cultural, ni política, ni económicamente ajenos a la crisis. Hechos que deberían hacernos reflexionar en todo lo que se ha cedido ante quienes se lucran con el consumismo sanitario y reconocer que la iatrogenia se ha convertido en un gran problema de salud pública de los países desarrollados ${ }^{11}$.

Para concluir, es pertinente recordar que tener una "vida buena, con y para los demás, en instituciones justas"12 es la aspiración de la ética. Que los más vulnerables puedan tener esa "vida buena" depende en gran parte de que sigamos manteniendo, también hoy, los compromisos profesionales y la calidad de nuestro trabajo. Pero sin duda, políticos y gestores deben entender que, sin justicia, no puede haber ninguna otra virtud.

\section{ABREVIATURAS}

OMS: Organización Mundial de la Salud.

\section{BIBLIOGRAFÍA}

1. WHO Regional Committee for Europe. Health 2020 a European policy framework supporting action across government and society for health and wellbeing. 2012 [en línea] [consultado el 10/11/2012] Disponible en http://goo.gl/LGZOt

2. Frenk J, de Ferranti D. Universal health coverage: good health, good economics. Lancet. 2012;380:862-4

3. Pardell H, Gual A, Oriol-Bosch A. ¿Qué significa ser médico, hoy? Med Clin (Barc). 2007;129(1):17-22.

4. Borrell-Carrio F, Epstein RM, Pardell Alentà H. Profesionalidad y profesionalismo: fundamentos, contenidos, praxis y docencia. Med Clin (Barc). 2006; 127(9):337-42. 
5. Martínez González C. La mirada social del pediatra. An Pediatr (Barc). 2010;73(5):229-32.

6. La infancia en España, 2012-2013. El impacto de la crisis en los niños. Madrid: Unicef España; 2012 [en línea] [consultado el 15/12/2012]. Disponible en http://goo.gl/wl3wV

7. Nussbaum MC. Premio Príncipe de Asturias de Ciencias Sociales, 2012. Fundación Príncipe de Asturias [en línea] [consultado el 20/12/2012]. Disponible en http://goo.gl/NnkHY

8. Colectivo loé y Heliconia. Motivos de discriminación en España; estudio exploratorio. Madrid: Dirección General contra la Discriminación, Ministerio de Igualdad; 2009 [en línea] [consultado el 20/12/2012]. Disponible en http://goo.gl/O56Uu

9. Laparra M, Pérez Eransus B, Lasheras R, Carbonero Gamundí MA, Guinea-Martín D, Zugasti N, et al. Cri- sis y fractura social en Europa. Causas y efectos en España. Barcelona: Obra Social "La Caixa"; 2012 [en línea] [consultado el 10/11/2012]. Disponible en http://goo.gl/z7ZGj

10. Marmot M, Allen J, Bell R, Bloomer E, Goldblatt P, on behalf of the Consortium for the European Review of Social Determinants of Health and the Health Divide. WHO European review of social determinants of health and the health divide. Lancet. 2012;380:1011-29.

11. Hernández Aguado I, Benavides FG, Porta M. Políticas de salud que ahorran y crean riqueza. El País, 10 de noviembre de 2012 [en línea] [consultado el 10/11/2012]. Disponible en http://goo.gl/DknyZ

12. Ricoeur P. Lo justo 2. Estudio, lecturas y ejercicios de ética aplicada. Madrid: Editorial Trotta; 2008. p. 11. 